\title{
УДК 341.1
}

\section{LEGAL CHARACTERISTICS OF ACTS OF THE ORGANIZATION FOR ECONOMIC COOPERATION AND DEVELOPMENT ПРАВОВАЯ ХАРАКТЕРИСТИКА АКТОВ ОРГАНИЗАЦИИ ЭКОНОМИЧЕСКОГО СОТРУДНИЧЕСТВА И РАЗВИТИЯ}

Tychyna V.P. / Tычина В.П. candidate of science of law, as.prof. / к.юр.н., доu. Zhytomyr Polytechnic State University, Zhytomyr, 103, Chudnivska str., 10005

\begin{abstract}
Аннотация. В статье предоставлена правовая характеристика актов Организации экономического сотрудничества и развития. Исследование основывается на результатах исследования содержания этих правовых документов. Установлено, что по сфере действия они могут быть внутренними и внешними, а их адресатами могут быть как государствачлены, так и третьи государства, и международные организации. Выяснено, что подавляюшее большинство актов ОЭСР содержат нормы «мягкого права». Выявлено, что помимо правовых и политических актов важное значение имеют документы, отражающие результаты уставной деятельности ОЭСР из широкого круга внутригосударственных и международных отношений касательно отдельной страны или группь стран. Они не только содержат много иенной аналитической информащии, но и могут становиться основанием принятия правовых и политических актов Организации, а также влиять на национальное законодательство и учитываться в практической деятельности других международных организаичии.
\end{abstract}

Ключевые слова: международные организации, Организация экономического сотрудничества и развития, акть Организации экономического сотрудничества $и$ развития, решения и рекомендации ОЭСР.

\section{Вступление.}

Одной из особенностей современного этапа развития международных отношений является расширение круга субъектов международного права, а также диверсификация правовых инструментов, избираемых ими для регулирования. Как отмечает М. В. Буроменский, «в международном праве на фоне вызовов XXI века международные организации превратились во влиятельного игрока, получив возможность влиять на международный правотворческий процесс. И международное право признало такую роль за международными организациями» [1, с. 5].

Международные межправительственные организации выступают участниками двух основных стадий процесса международно-правового регулирования: правотворчества и правоприменения. Правотворческий процесс международных организаций включает деятельность, направленную на создание правовых норм, а также их дальнейшее совершенствование, изменение или отмену. В процессе правоприменения происходит реализация норм международного права, направленная на достижение ее цели и задач.

Участие международных организаций в процессе международноправового регулирования имеет индивидуальный характер и может отличаться объемом, направлениями и формами. Эта специфика определяется их уставами и общими рамками международного права. Собственно, уставные документы и определяют, какие акты могут принимать международные 
организации для реализации цели создания, достижения целей и выполнения задач, какова их юридическая сила и сфера действия. Стоит согласиться, что каждая международная организация создает собственную правовую систему [2, с. 147].

\section{Цель работы.}

В данном контексте возникает потребность в определении эффективности и действенности правового регулирования, которое осуществляет Организация экономического сотрудничества и развития (далее - ОЭСР или Организация).

Среди исследователей, изучавших вопросы международного правотворчества, действенности правового регулирования, которые осуществляются международными организациями, стоит назвать Т.Н. Анакину, В.Г. Буткевича, Г.М. Вельяминова, М.Ю. Велижанину, И.И. Лукашука, Е.Е. Мавромати, В.В. Мицика, В.И. Муравьева, Т.Н. Нешатаеву, О.Я. Трагнюк, Г.И. Тункина, О.Н. Шпакович, Е.А. Шибаеву, И.В. Яковюка и многих других. Однако вопрос о правовой природе актов ОЭСР остается без внимания ученых.

Задачи исследования: определение правовой природы актов, принимаемых ОЭСР, предоставление их общей правовой характеристики и определение их влияния на правопорядки государств-членов Организации и третьих стран.

\section{Изложение основного материала.}

В соответствии со ст. 5 Конвенции об Организации экономического сотрудничества и развития от 14.12.1960 г. [3] (далее - Конвенция ОЭСР 1960 г.) в рамках ОЭСР могут приниматься два основных вида актов: 1) решения (англ. decisions); 2) рекомендации (англ. recommendations). Такие акты от имени ОЭСР принимает Совет, в состав которого входят представители всех странчленов на уровне министров или постоянных представителей (ст. 7).

По общему правилу, решения имеют общий характер и являются обязательными для всех государств-членов. Согласно п. а правила 18 Правил процедуры ОЭСР 2013 г. [4] решение Совета ОЭСР может иметь различное назначение и заключаться как (1) юридически обязательный для государствчленов акт, который должен быть имплементирован в соответствии с национальными конституционными процедурами; (2) акт, регулирующий отношения с третьими странами или международными организациями, или которым утверждаются соглашения с государствами-членами и третьими странами или международными организациями; (3) акт касательно внутренних отношений, касающихся работы Организации. Итак, по сфере действия решение может быть как внутренним актом, так и внешним, а его адресатами могут быть как государства-члены, так и третьи страны и международные организации.

Примерами актов первой группы являются Решение Совета о контроле за трансграничной перевозкой отходов, предназначенных для операций по рекуперации от 18.11.2008 г.; Третье пересмотренное Решение Совета от 11.07.2013 г. относительно национального режима; Решение Совета о создании Схемы ОЭСР по сертификации лесного репродуктивного материала в международной торговле от 20.10.2016 г., которое направлено на сохранение 
видового многообразия, стимулирования производства и использования семян лесных деревьев или растений и др.

Решения второй группы направлены на поощрение международного сотрудничества на основе взаимной выгоды и справедливых преимуществ, что имеет целью ускорение экономического и социального развития как государств-членов, так и не членов ОЭСР. Одним из неотъемлемых составляющих такого сотрудничества, как отмечает в своем исследовании М. Ю. Велижанина, является принятие международными организациями своеобразных программ развития, стандартов, правил, совместных заявлений, соглашений, деклараций, выполняемых участниками добровольно на основе принципа добросовестности [5, с. 52-58]. Примером актов второй группы является Решение Совета ОЭСР об углублении сотрудничества с Украиной от 12.03.2014 г. [15], ставшее правовым основанием заключения от имени ОЭСР Меморандума о взаимопонимании между Правительством Украины и Организацией экономического сотрудничества и развития относительно углубления сотрудничества от 07.10.2014 г. [16].

К третьей группе относятся решения, определяющие порядок функционирования ОЭСР и принимаемые Советом в форме резолюций (пп. «іiі» п. «а» правила 18 Правил Процедуры). Они образуют так называемое «внутреннее право международной организации». Такие акты могут приниматься по вопросам участия в органах ОЭСР и приема новых членов в Организацию, утверждения ежегодного регулярного бюджета ОЭСР, создания вспомогательных органов, процедуры принятия актов Организации, внутренних правил относительно штатных работников, обслуживающего персонала и тому подобное. Одним из примеров таких решений является Пересмотренная Резолюция Совета о новой управленческой структуре Организации от 15.07.2015 г. [7].

Достаточно интересной практикой, используемой ОЭСР, является принятие «решений-рекомендаций», то есть актов, одновременно сочетающих юридически обязательные и рекомендательные нормы. Одним из примеров является Решение-рекомендация Совета по международной туристической политике от 27.11.1985 г. [6]. В частности, в ее ч. II предоставляются рекомендации государствам-членам: избегать мер, препятствующих перемещению путешественников в свои страны и из них; избегать мер, искажающих конкуренцию в туристических отраслях государств-членов; гарантировать предприятиям, которые находились под контролем иностранных государств, право осуществлять деятельность, связанную с туризмом, и относиться к ним не менее благоприятно, чем к национальным предприятиям в подобных ситуациях; пытаться уменьшить свои административные требования, формальности и количество документов, которые применяются к путешественникам, и рассматривать их в наиболее быстрый, последовательный и удобный способ и т.п. В приложении I к этому акту предоставлен перечень обязательств государств-членов касательно таможенных процедур в отношении путешественников, международного оборота частных транспортных средств, пользования кемпингами, временного ввоза товаров, связанных с туризмом. 
Помимо решений основным актом, который может приниматься Советом ОЭСР, являются рекомендации-акты, которые адресуются государствам-членам и не являются юридически обязательными. Они подаются государствам-членам на рассмотрение для возможности их дальнейшего выполнения, если это будет считаться ими уместным. Соответственно, государства-члены имеют право, а не обязанность, осуществить их имплементацию.

В соответствии с п. 13 раздела II Резолюции 2015 г. [7] рекомендации принимаются Советом на основе консенсуса. Если же государство не намерено соблюдать рекомендации, что per se не является обязательным, оно, как правило, воздерживается от участия в его принятии. Если Рекомендация Совета (или ее часть) не касается определенных Членов, то в тексте правового акта указываются Члены Организации, которых они не касаются, и условия, при которых Рекомендация (или ее часть) может быть применена, кроме случаев, когда указано иное. В случае если Член Организации воздержался от голосования при принятии Рекомендации, другие государства-члены могут согласовать, чтобы Рекомендация применялась между ними временно, до выражения мнения указанного Члена. Если государство-член «не присоединяется к принятой Рекомендации в течение периода, определенного Советом, последний решает вопрос об обязательности положений правового акта для других присоединившихся Членов» (п. b правила 20 Правил Процедуры). Отсутствие государства-члена при принятии Рекомендации при условиях, указанных в пункте b правила 20 Правил Процедуры, не отменяет эту новую Рекомендацию [4].

Стоит подчеркнуть, что, хотя рекомендации не являются формально обязательными для государств-членов, они наделены значительной моральнополитической силой и имеют безоговорочный авторитет, поскольку выражают общую позицию всех членов Организации. В связи с этим последние стараются придерживаться их предписаний на практике. Кроме того, рекомендательные акты Совета ОЭСР можно охарактеризовать как мягкий и гибкий регулятор, позволяющий странам использовать закрепленные в них нормы к конкретным обстоятельствам, что часто значительно практичнее, чем попытки унифицировать в едином документе разнообразные и часто противоположные национальные практики. Учитывая такие преимущества количество рекомендаций значительно превышает количество решений.

На сегодня Советом ОЭСР был принят ряд рекомендаций в сфере: корпоративного управления (Рекомендация Совета С(2015)85 о руководящих принципах корпоративного управления государственных предприятий); правил конкуренции (Рекомендация Совета 0408 по международному сотрудничеству по вопросам расследования преступлений в сфере конкуренции); государственных закупок (Рекомендация по государственным закупкам); налогообложения (Рекомендация Совета 0407 касательно стандарта автоматического обмена финансовой информацией в налоговой сфере); государственной службы (Рекомендация Совета 0445 по вопросам лидерства и эффективности государственной службы); защиты окружающей среды (Рекомендация Совета 0446 по противодействию незаконной торговле 
пестицидами; Рекомендация Совета С(2016)174 по вопросам водных ресурсов); здравоохранения (Рекомендация Совета 0433 по управлению данными в области здравоохранения) и тому подобное.

Кроме Совета как высшего руководящего органа ОЭСР юридически обязательные и рекомендательные акты могут приниматься его вспомогательными органами и аффилированными структурами. Особенности юридической силы таких актов определяются их регламентами и правилами процедуры, которые в свою очередь утверждаются решением Совета ОЭСР.

Обычно юридически обязательные акты (решения) касаются так называемого внутреннего права, регулирующих порядок работы соответствующего органа, статус их должностных лиц, финансовые положения и бюджет, особенности правового положения государств-членов и возможность участия третьих стран или международных организаций и тому подобное.

Акты, не имеющие юридически обязательной силы, могут иметь различные наименования. Термин «декларация» обычно выбирается для акта, который определяет общие принципы или долгосрочные задачи, имеет особое морально-политическое значение (на что делается особый упор в тексте) и в основном принимается на уровне министров государств-членов в комитетах Организации. Одной из наиболее влиятельных является Декларация о размывании налоговой базы и выводе прибыли из-под налогообложения от 29.05.2013 г. [8] (распространенное неофиц. название - Декларация BEPS (англ. Base Erosion and Profit Shifting), ставшая основанием для принятия Плана действий, состоящего из 15 мер, направленных на обеспечение честной налоговой конкуренции между субъектами хозяйствования разных стран.

Учитывая то, что большинство актов ОЭСР не являются юридически обязательными, по мнению многих западных исследователей, их следует рассматривать преимущественно как «мягкое» право (В. Альберто (V. Alberto), Л. Даварнеяд (L. Davarnejad), К. Ласински-Сулецки (K. Lasiński-Sulecki), А. Сантер (А. Santer) и др.) [9].

Помимо большого количества рекомендаций как правовых актов в рамках ОЭСР могут приниматься и другие юридически необязательные акты, возлагающие на страны лишь политические обязательства (политические акты). Наиболее распространенными среди них являются договоренности (англ. arrangements) и акты о взаимопонимании (англ. understandings). Они фиксируют достигнутый уровень согласия государств-членов по актуальной проблематике, определяют согласованную модель ее регулирования на основе лучших национальных практик. К ним могут присоединяться третьи страны и международные организации. Существенным отличием между договоренностями и актами является степень детализации: договоренности являются более детализированными и сравнительно большими по объему документами.

Одним из примеров является Договоренность об официально поддерживаемых экспортных кредитах от 26.07.2018 г. [17], которая направлена на создание равных условий и поощрение конкуренции среди экспортеров на основании качества и цены товаров и экспортных услуг, а не на 
наиболее выгодных официально поддерживаемых финансовых условиях. Среди актов о взаимопонимании можно выделить Международный акт о взаимопонимании принципов морского транспорта от 28.10.1999 г. [18], которым согласованы принципы открытых рынков, конкурентоспособности, услуг, а также стандарты безопасности и контроля за загрязнением и тому подобное.

Среди неправовых актов важное значение имеют доклады вспомогательных органов и аффилированных структур ОЭСР с широкого круга внутригосударственных и международных отношений касательно отдельной страны или группы стран. Они не только содержат много ценной аналитической информации, но и могут становиться основанием принятия правовых актов Организации, а также влиять на национальное законодательство.

Среди таких актов особое место занимают экспертные оценки (англ. peer reviews) - мониторинговые документы, принимаемые в результате изучения деятельности или практики конкретного государства или группы государств в определенной сфере и содержат рекомендации, основанные на правовых актах ОЭСР и направленные на улучшение их государственно-правового развития без создания для государства правовых обязательств.

Они могут приниматься как в отношении государств-членов, так и третьих стран. Оценивание осуществляется иностранными экспертами профильных структурных единиц ОЭСР. Формат рецензирования государства предусматривает открытый с ней партнерский диалог, совместное обсуждение, взаимный поиск путей решения актуальных проблем и определение соответствующего плана действий. C периодичностью, определяемой по взаимному согласию сторон, предусмотрено принятие отчета о результатах выполнения предоставленных рекомендаций.

Как показывает практика, экспертные осмотры имеют важное значение для страны как указатели относительно необходимых государственно-правовых реформ, а также учитываются зарубежными странами и их субъектами хозяйствования при изучении возможности доступа к национальному рынку, инвестирования, усиления сотрудничества и тому подобное и оценки возможных рисков. Кроме того, положения экспертных осмотров, особенно в части рекомендаций, могут приниматься во внимание другими международными организациями при оценивании выполнения государством своих международных обязательств или принятия решения об углублении сотрудничества.

Стоит отметить, что правовые и политические акты ОЭСР могут стать частью или определенным этапом в международном правотворческом процессе, часто служат основанием для принятия международных договоров в рамках или при участии этой Организации. В частности, стоит указать на Конвенцию о борьбе с подкупом иностранных должностных лиц при осуществлении международных коммерческих сделок от 17.12.1997 г. [10], основанной, как сказано в ее преамбуле, на Рекомендации Совета ОЭСР о борьбе с подкупом при осуществлении коммерческих сделок от 23.04.1997 г. 
Заметим, что акты, принятые в рамках или при участии Организации, могут иметь существенное влияние на формирование, развитие и совершенствование законодательства не только государств-членов, но и третьих стран и даже акты, принимаемые в рамках других международных организаций. В связи с этим отдельными исследователями ОЭСР характеризуется как «лаборатория международных стандартов», «инкубатор новых идей», «точка концентрации лучших практик» или «международный правотворец» (Н. Бонуччи (N. Bonucci); Р. Вольф (R. Wolfe); Р. Вудворд (R. Woodward).

Так, Решение Совета ОЭСР о принятии Кодекса либерализации операций с капиталом от 12.12.1961 г. [19] и Кодекса либерализации текущих невидимых операций от 12.12.1961 г. [20] стали основой правовой системы, созданной в рамках ВТО. Кроме того, указанные решения до принятия Генерального Соглашения по торговле услугами 1995 г. выполняли функцию единого международного многостороннего договора в сфере инвестирования.

Масштабное влияние актов ОЭСР наблюдается на право Европейского Союза, учитывая тесные правовые отношения между этими организациями, участие Европейской Комиссии в работе всех органов ОЭСР и присоединения Союза к ряду международных договоров и политических договоренностей, заключенных в рамках или под эгидой этой Организации. В частности, Европейский Союз широко использует юридически обязательные и рекомендательные акты ОЭСР, ее аналитические исследования, экспертные исследования, статистические данные в разработке законодательных инициатив и принятии нормативных актов, планировании и оценке эффективности своих программ, оценке прогресса государств-членов в выполнении своих обязательств.

Так, со вступлением в силу Лиссабонского договора 01.12.2009 г. иностранное прямое инвестирование и защита инвестиций стали центральными вопросами внешней коммерческой политики ЕС. Европейская Комиссия в своем сообщении «О всеобъемлющей европейской международной инвестиционной политике» от 07.07.2010 г. [11] подчеркнула, что «при разработке общей инвестиционной политики она будет учитывать «обширную аналитическую работу международных организаций, прежде всего ОЭСР». Она также отметила, что «будет придерживаться принципов и стандартов об ответственном бизнес-поведении, в частности определенных в Наставлениях ОЭСР относительно многонациональных предприятий».

Поэтому ряд правовых механизмов, разработанных ОЭСР, рецепиированы во вторичном законодательстве ЕС. В частности, Регламентом Европейского Парламента и Совета 1233/2011 относительно применения некоторых руководящих принципов в сфере официально поддерживаемых экспортных кредитов от 16.11.2011 г. [12] имплементировано Договоренность об официально поддерживаемых экспортных кредитах от 26.07.2018 г. [13] и связанных с ней актов о взаимопонимании, на что делается прямое указание в преамбуле.

Кроме того, акты ОЭСР, а также ее аналитические документы могут 
использоваться Судом ЕC как источник толкования вторичного законодательства Европейского Союза. В целом же в своей практике Суд придерживается принципа, что нормы права ЕС, основанные на актах ОЭСР, должны толковаться в свете положений таких актов. Так, в решении С-279/93 от 14.02.1995 г. в деле Finanzamt Köln-Altstadt v Roland Schumacker [14] Суд ЕС использовал положения Модельного Соглашения ОЭСР об избежании двойного налогообложения как «доказательство всеобщей практики, отражающий обычные нормы международного права в сфере налогообложения» при определении налогового резидентства лица (п. 32 Решения).

\section{Выводы.}

Подводя итог нашего исследования, можно сделать следующие основные выводы:

1. Согласно Конвенции об ОЭСР 1960 г., правил процедуры ее руководящих и вспомогательных органов для достижения цели и задач Организацией экономического сотрудничества и развития могут приниматься как правовые акты (решения и рекомендации), так и политические акты (декларации, соглашения, акты о взаимопонимании и т.д.), отражающие лучшие национальные практики или новые подходы и оказывающие регулирующее влияние на национальное право государств-членов и третьих стран, а также международных организаций, с которыми Организация осуществляет международное сотрудничество. Кроме того, большое значение имеют документы, которые принимаются в результате уставной деятельности ОЭСР (тематические обзоры, экспертные оценки и др.), которые могут ложиться в основу ее правовых и политических актов.

2. Большинство актов ОЭСР содержат нормы «мягкого права», которые не создают правовых обязательств для государств-членов. Такой подход является наиболее компромиссным учитывая реалии сложных геополитических условий, когда достижение консенсуса в принятии международно-правовых актов юридически обязательной силы является довольно сложной практической задачей.

3. Правовые и политические акты ОЭСР могут стать частью или определенным этапом в международном правотворческом процессе, и могут выступать основанием для принятия международных договоров в рамках или при участии этой Организации. Кроме того, акты, принятые в рамках или при участии ОЭСР, могут иметь существенное влияние на формирование, развитие и совершенствование законодательства как государств-членов, так и третьих стран, а также актов, принимаемых в рамках других международных организаций.

4. Масштабное влияние актов ОЭСР наблюдается на право Европейского Союза, учитывая тесные правовые отношения между этими организациями. Наиболее значительное влияние испытали такие сферы права ЕС, как общая торговая политика и внутренний рынок, в том числе правила конкуренции, налогообложение, государственная помощь и тому подобное. Европейский Союз широко использует юридически обязательные и рекомендательные акты 
ОЭСР, еe аналитические исследования, экспертные исследования, статистические данные в разработке законодательных инициатив и принятии нормативных актов, планировании и оценке эффективности своих программ, оценке прогресса государств-членов в выполнении своих обязательств.

\section{Литература:}

1. Буроменский М.В. Международное право на фоне вызовов XXI века. Актуальные проблемы современного международного права: сб. науч. ст. по материалам I Харьков. междунар.-прав. чтений, посвященных памяти профессоров Н. В. Яновского и В. С. Семенова, Харьков, 27 ноября 2015 г.: в 2 ч. редкол.: А. П. Гетьман, И.В. Яковюк, В.И. Самощенко и др. Харьков: Право, 2015. Ч. 1. С. 5-17.

2. Шпакович О.Н. Влияние актов международных организаций на внутренние правопорядки государств-членов: научный доклад. Актуальные проблемы международных отношений. Вып. 101 (Ч. І). Киев, 2011. С. 106-110.

3. Convention on the Organization for Economic Cooperation and Development, Paris 14th December 1960. OECD Home. Paris, 1965. URL:

http://www.oecd.org/general/conventionontheorganisationforeconomiccooperationan ddevelopment.htm

4. Rules of Procedure of the Organization, Paris October 2013. OECD Home: OECD Internal Rules and Regulations. Paris, 2013. URL: https://www.oecd.org/legal/Rules\%20of\%20Procedure\%20OECD\%20Oct\%202013.p df

5. Велижанина М. Ю. «Мягкое право»: его сущность и роль в регулировании международных отношений: автореф. дис. ... канд. юрид. наук. Москва, 2007. 19 с.

6. Decision-Recommendation of the Council on International Tourism Policy, Paris 27th December 1985 - 0222: OECD Decisions, Recommendations and other Instruments of the Organization for Economic Cooperation and Development. Paris: OECD Publishing, 1985. URL: https://legalinstruments.oecd.org/en/instruments/OECD-LEGAL-0222

7. Resolutions of the Council on the Governance of the Organization, Paris 15th July 2015: OECD Official documents. Paris: OECD Publishing, 2015. URL:http://www.oecd.org/officialdocuments/publicdisplaydocumentpdf/?cote $=\mathrm{C}(20$ 15)100\&docLanguage $=$ En

8. Declaration on Base Erosion and Profit Shifting of 29.05.2013. OECD Legal Instruments. OECD Official Documents. Paris: OECD Publishing, 2013. URL: https://legalinstruments.oecd.org/en/instruments/OECD-LEGAL-0399

9. Santner A. Soft Law Mechanism for Corporate Responsibility: How the Updated Guidelines for Multinational Enterprises promote business for the future. The George Washington International Law Review. Washington, 2011. Vol. 43, Number 2. P. 375-388.

10. Convention on Combating Bribery of Foreign Public Officials in International Business Transactions of 17.12.1997. OECD Official Documents. Paris: OECD Publishing, 1997. 
URL:https://legalinstruments.oecd.org/en/instruments/OECD-LEGAL-0293

11. Towards a comprehensive European international investment policy:

European Commission of 07.07.2010. URL:

http://trade.ec.europa.eu/doclib/docs/2010/july/tradoc_146307.pdf

12. Regulation (EU) No 1233/2011 of the European Parliament and of the

Council of 16.11.2011 on the application of certain guidelines in the field of officially supported export credits and repealing Council Decisions 2001/76/EC and 2001/77/EC. URL: https://publications.europa.eu/en/publication-detail//publication/e1c17790-f4f0-49be-b6e6-e6f9864f2438/language-en

13. Arrangement on Officially Supported Export Credits of 26.07.2018. OECD Official Documents. Paris: OECD Publishing, 2018. URL: http://www.oecd.org/officialdocuments/publicdisplaydocumentpdf/?doclanguage=en \&cote $=\operatorname{tad} / \operatorname{pg}(2018) 8$

14. Judgment of the Court of Justice in case C-279/93 of 14.02 .1995 «Finanzamt Köln-Altstadt v Roland Schumacker». URL:

http://curia.europa.eu/juris/showPdf.jsf?text=\&docid=99137\&pageIndex $=0$ \&doclang $=$ EN\&mode $=1$ st\&dir $=\&$ occ $=$ first $\&$ part $=1 \&$ cid $=953399$

15. Council Decision to deepen existing cooperation with Ukraine of 12.03.2014. OECD Countries: Ukraine. URL:

https://www.oecd.org/countries/ukraine/

16. Меморандум о взаимопонимании между Правительством Украины и Организацией экономического сотрудничества и развития по углублению сотрудничества от 07.10.2014 г. Официиальный вестник Украиныл. 2014. № 93. Ст. 1077.

17. Arrangement on Officially Supported Export Credits of 26.07.2018. OECD Official Documents. Paris: OECD Publishing, 2018. URL: http://www.oecd.org/officialdocuments/publicdisplaydocumentpdf/?doclanguage=en $\&$ cote $=\operatorname{tad} / \operatorname{pg}(2018) 8$

18. International Understanding on Maritime Transport Principles of 28.10.1999. OECD Official Documents. Paris: OECD Publishing, 1999. URL: https://legalinstruments.oecd.org/public/doc/314/314.en.pdf

19. OECD Code of Liberalization of Capital Movements of 12.12.1961: OECD Official Documents. OECD Investment policy.

Paris: OECD Publishing, 2016. URL:

http://www.oecd.org/daf/inv/investmentpolicy/CapitalMovements WebEnglish.pdf

20. OECD Code of Liberalization of Current Invisible Operations of 12.12.1961: OECD Official Documents. OECD Investment policy. Paris: OECD Publishing. 2016. URL: http://www.oecd.org/daf/fin/privatepensions/InvisibleOperations_WebEnglish.pdf

Summary. The article provides legal characteristics of acts of the Organization for Economic Cooperation and Development. The investigation is based on the results of research of these legal documents content. It was established that they can be internal or external in the scope, and their addressees can be member states as well as third states and international organizations. The fact that the vast majority of OECD acts contain norms of "soft law" was found out. It was discovered that in addition to legal and political acts, documents reflecting the results of the OECD's statutory 
activities on a wide range of domestic and international relations regarding an individual country or group of countries are important. They not only contain a lot of valuable analytical information but can also become the basis for the adoption of legal and political acts of the Organization, as well as influence national legislation and be taken into account in the practical activities of other international organizations.

Keywords: international organizations, Organization for Economic Cooperation and Development, acts of the Organization for Economic Cooperation and Development, decisions and recommendations of the OECD.

Статья отправлена: 10.05.2021 г.

(C) Тычина В.П. 